\title{
Heat Dissipation Modeling of In-Situ Conversion Process of Oil Shale
}

\author{
Atif Zafar ${ }^{1,2}$, Yuliang Su${ }^{1}$, Wendong Wang ${ }^{1}$, Syed Ghufran Alam ${ }^{2}$, Danish Khan ${ }^{3}$, \\ Muhammad Yasir ${ }^{3}$, Ayman Alrassas' ${ }^{1}$ Ishaq Ahmad1 \\ ${ }^{1}$ School of Petroleum Engineering, China University of Petroleum (East China), Qingdao, China \\ ${ }^{2}$ Department of Petroleum Technology, University of Karachi, Karachi, Pakistan \\ ${ }^{3}$ School of Geosciences, China University of Petroleum (East China), Qingdao, China \\ Email: atif_zafar1984@yahoo.com
}

How to cite this paper: Zafar, A., Su, Y.L., Wang, W.D., Alam, S.G., Khan, D., Yasir, M., Alrassas, A. and Ahmad, I. (2020) Heat Dissipation Modeling of In-Situ Conversion Process of Oil Shale. Open Journal of Yangtze Gas and Oil, 5, 46-53.

https://doi.org/10.4236/ojogas.2020.52005

Received: October 19, 2019

Accepted: March 17, 2020

Published: March 20, 2020

Copyright $\odot 2020$ by author(s) and Scientific Research Publishing Inc. This work is licensed under the Creative Commons Attribution International License (CC BY 4.0).

http://creativecommons.org/licenses/by/4.0/

\begin{abstract}
In-situ conversion of process of oil shale has been technically proven as a pilot field project. Gradually heating the reservoir by using subsurface electric heaters converts the oil shale reservoir kerogen into oil, gas and other producible components. This process also enhances the internal energy of the porous media as well as the subsurface fluid. Heat is transmitted in the reservoir within each fluid by different processes i.e., due to the flow of fluid called advective process, and due to molecular diffusion where dispersive and diffusive processes take place. Heat transfer through conduction and convection mechanisms in the porous media are modeled mathematically and numerically incorporating the advective, dispersive and diffusive processes in the reservoir. The results show the production of oil and gas as a result of conversion of kerogen due to modeled heat dissipation.
\end{abstract}

\section{Keywords}

Heat Dissipation, In-Situ Conversion, Oil Production, Oil Shale

\section{Introduction}

The demand of energy has been increasing day by day which opened new windows of research in the field of petroleum exploration and production. New methods of development for conventional and unconventional reservoirs have been discussed and implemented vastly during the last couple of decades. Oil shale reserves in the world are more abundant than any conventional oil reserves. The United States of America has the major oil shale reserves in the world [1]. 
Oil shale has a component called kerogen which is the main source of producing hydrocarbon liquid and gas. This component is found in solid state. At some specific temperature range, this component starts to liquefy and gasify leaving behind some pre-char, char and coke products [2]. Normally, retorting the oil shale is carried out to the surface which is called ex-situ retorting of kerogen. In this process, oil shale is mined and brought to the surface for retorting process [3]. This process has many disadvantages. First of all, this process is valid for exposed oil shale or/and shallow depth reservoirs because deep mining for oil shale retorting is very risky and almost impossible. Secondly, this process is not considered as environment friendly because of mining which requires a larger land area to use. Thirdly, the production of big amount of $\mathrm{CO}_{2}$ gas and other impurities is also considered as a problem while left behind coke, char and pre-char are also very hazardous for environment and need a proper disposal [4] [5] [6] [7].

On the other hand, the in-situ conversion process of kerogen is a relatively new technique which allows the retorting of kerogen into liquid and gas beneath the surface. Then these converted hydrocarbons are produced like at any other conventional petroleum reservoir [8] [9] [10] [11] [12]. This process has many advantages over ex-situ methods. It is viable for deeper deposits of oil shale formation. The quality of crude oil extracted by in-situ conversion process is usually better than ex-situ process. Additionally, this process is relatively environmentally friendly [13] [14] [15] [16].

The down-hole subsurface electric heaters are installed in heating wells during the in-situ conversion process of kerogen which provides slow heating to the formation and temperature is gradually increased upto $370^{\circ} \mathrm{C}$ [17] [18]. To accurately model the heat dissipation within the oil shale formation it is required to develop a mathematical and numerical model which can acknowledge all means of heat transfer i.e. convection, conduction, dispersion, advection and diffusion.

In this paper, the heat dissipation is modeled by considering all the transportation processes of porous media and generated fluid. This approach will help to make the in-situ conversion process viable and feasible to adopt practically.

\section{Mathematical Formulation}

Introducing heat to oil shale reservoir enhances the internal energy of fluid as well as of the porous media. Heat is transmitted in the reservoir by different processes i.e., due to the flow of fluid called an advective process, due to molecular diffusion through dispersive and diffusive processes. The total mass transport through these processes in a fluid is best described by generalized Fick's law (Equation (1)).

$$
f_{\beta}^{k}=\rho_{\beta} X_{\beta}^{k} v_{\beta}-D_{\beta}^{k} \nabla\left(\rho_{\beta} X_{\beta}^{k}\right)
$$

where $\beta$ is a fluid phase, $k$ is a mass component index, $f_{\beta}^{k}$ is aggregated flux, $\rho_{\beta}$ is fluid density, $X_{\beta}^{k}$ is $k_{\mathrm{th}}$ component fluid mole fraction, $D_{\beta}^{k}$ is hydro-dynamic dispersion. For multiphase flow, $\mathrm{Wu}$ and Pruess [14] have ex- 
tended the hydro-dynamic dispersion as given below (Equation (2)).

$$
D_{\beta}^{k}=\alpha_{\mathrm{T}}^{\beta}\left|v_{\beta}\right| \delta_{i j}+\left(\alpha_{\mathrm{L}}^{\beta}-\alpha_{\mathrm{T}}^{\beta}\right) \frac{v_{\beta} v_{\beta}}{\left|v_{\beta}\right|}+\varnothing S_{\beta} \tau d_{\beta}^{k} \delta_{i j}
$$

where $\alpha_{\mathrm{T}}^{\beta}$ and $\alpha_{\mathrm{L}}^{\beta}$ are dispersivities (transverse and longitudinal), $\tau$ is tortuosity, $\delta$ is Kronecker delta function, $d$ is the molecular diffusion coefficient.

Convection and conduction are the main heat transportation mechanisms through a porous media. The flow of all fluids (i.e., oil, gas and water) present in the reservoir, transports heat through convection method whereas temperature gradient disperses through conduction as per Fourier's law. The total heat flux in the porous media is given by [8] (Equation (3)).

$$
F^{T}=\sum_{\beta}\left(h_{\beta} \rho_{\beta} v_{\beta}\right)-\sum_{\beta} \sum_{k}\left(h_{\beta}^{k} D_{\beta}^{k} \cdot \nabla\left(\rho_{\beta} X_{\beta}^{k}\right)\right)-\left(K_{\mathrm{T}} \nabla T\right)
$$

where $F^{T}$ is total heat flux, $h$ is specific enthalpy and $K_{\mathrm{T}}$ is thermal conductivity. For each mass component $k$, mass conservation and energy conservation equations, with the coupling of convection and conduction mechanisms of heat transfer, are as follows [8] (Equations (4) and (5)).

$$
\begin{aligned}
& \frac{\partial}{\partial t}\left[\varnothing \sum_{\beta}\left(\rho_{\beta} S_{\beta} X_{k}^{\beta}\right)\right]=-\sum_{\beta} \nabla \cdot\left(\rho_{\beta} X_{\beta}^{k} v_{\beta}\right)+\sum_{\beta} \nabla \cdot\left(D_{\beta}^{k} \cdot \nabla\left(\rho_{\beta} X_{\beta}^{k}\right)\right)+q^{k} \\
& \frac{\partial y}{\partial x}\left[\sum_{\beta}\left(\varnothing \rho_{\beta} S_{\beta} U_{\beta}\right)+(1-\varnothing) \rho_{\mathrm{s}} U_{\mathrm{s}}\right] \\
& =-\sum_{\beta} \nabla \cdot\left(h_{\beta} \rho_{\beta} v_{\beta}\right)+\sum_{\beta} \sum_{\beta} \nabla \cdot\left(h_{\beta}^{k} D_{\beta}^{k} \cdot \nabla\left(\rho_{\beta} X_{\beta}^{k}\right)\right)+\nabla \cdot\left(K_{\mathrm{T}} \nabla T\right)+q^{E}
\end{aligned}
$$

where $U$ is internal energy, subscript $s$ is for solid, $q$ is external sink/source, superscript $E$ is for energy. Using the concept of control volume Equations (4) and (5) are discretized as follows [8] (Equation (6)):

$$
\left(B_{i}^{k, n+1}-B_{i}^{k, n}\right) \frac{V_{i}}{\Delta t}=\sum_{j \in n_{i}} C_{i, j}^{k, n+1}+D_{i, j}^{k, n+1}, k=1,2, \cdots, N_{\mathrm{c}}+1 \text { and } i=1,2, \cdots, N
$$

The term $C_{i, j}^{k}$ in equation 6 represents the flow of mass fluxes by the result of dispersive and advective mechanisms as already described in Equation (1), and for heat transfer, it is described in Equation (3). where $B_{i}^{k, n}$ is accumulation, $C_{i, j}^{k, n+1}$ is flow and $D_{i, j}^{k, n+1}$ is source/sink term. For a further breakdown of term $B_{i}^{k, n}$ for mass-components and thermal energy are as follows [8] (Equations (7) and (8))

$$
\begin{gathered}
B_{i}^{k}=\left[\varnothing \sum_{\beta}\left(\rho_{\beta} S_{\beta} X_{\beta}^{k}\right)\right]_{i} \\
B_{i}^{N_{\mathrm{c}}+1}=\left[\sum_{\beta}\left(\varnothing \rho_{\beta} S_{\beta} U_{\beta}\right)+(1-\varnothing) \rho_{\mathrm{s}} U_{\mathrm{s}}\right]_{i}
\end{gathered}
$$

In terms of $i, j$ nodes, it is determined by the following equation [8] (Equation (9)).

$$
C_{i, j}^{k}=F_{\mathrm{A}, i j}^{k}+F_{\mathrm{D}, i j}^{k}
$$


where $F_{\mathrm{A}}$ is total mass fluxes occurred by advection and $F_{\mathrm{D}}$ is by dispersion. These two terms are calculated as follows [8] (Equations (10) and (11)).

$$
\begin{gathered}
F_{\mathrm{A}, i j}^{k}=A_{i j} \sum_{\beta}\left(X_{\beta}^{k}\right)_{i j+1 / 2} F_{\beta, i j} \\
F_{\mathrm{D}, i j}^{k}=-n_{i j} \cdot A_{i j} \sum_{\beta} D_{\beta}^{k} \cdot \nabla\left(\rho_{\beta} X_{\beta}^{k}\right)
\end{gathered}
$$

where $n$ is the unit vector, $F_{\beta}$ is mass flow term for phase $\beta$ and can be evaluated as follows [8] (Equation (12)).

$$
F_{\beta, i j}=\left(\frac{\rho_{\beta} k_{\mathrm{r} \beta}}{\mu_{\beta}}\right)_{i j+1 / 2} \gamma_{i j}\left(\varphi_{\beta j}-\varphi_{\beta i}\right)
$$

By applying the finite difference method, the total heat flux can be estimated by the following equation [8] (Equation (13)).

$$
C_{i j}^{N_{\mathrm{c}}+1}=A_{i j} \sum_{\beta}\left[\left(h_{\beta}\right)_{i j+\frac{1}{2}} F_{\beta, i j}\right]+\left(K_{T}\right)_{i j+\frac{1}{2}}\left(\frac{T_{j}-T_{i}}{d_{i}+d_{j}}\right)
$$

where subscript $i j+1 / 2$ means all properties of heat transfer and fluid flow are properly averaged at the interface of $i$ and $j$ nodes.

\section{Numerical Simulation}

A cartesian grid reservoir numerical model has been generated assuming one production and one injection wells as shown in Figure 1.

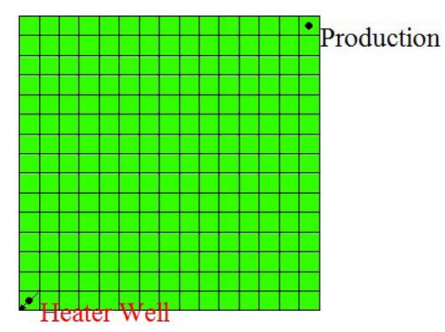

Figure 1. Cartesian grid reservoir numerical simulation model.

A commercial reservoir simulation software having thermal and compositional option was used for numerical simulation. Reservoir properties used in this study are shown in Table 1. Five years' simulation time was set up and heat was pumped to the reservoir through the heater well.

Table 1. Reservoir properties.

\begin{tabular}{ccc}
\hline Properties & Unit & Value \\
\hline Reservoir Pressure & Psi & 3256 \\
Reservoir Temperature & $\mathrm{F}$ & 247 \\
Depth & $\mathrm{ft.}$ & 8053 \\
Gross Thickness & $\mathrm{ft.}$ & 96 \\
Porosity & $\%$ & 5 \\
Permeability & $\mathrm{md}$ & 100 \\
\hline
\end{tabular}




\section{Results and Discussions}

Figure 2 shows the temperature distribution of the studied oil shale reservoir at initial condition. Temperature is homogenously distributed initially with the value of $247^{\circ} \mathrm{F}$. The heating is not started yet. This is the natural temperature of the reservoir.

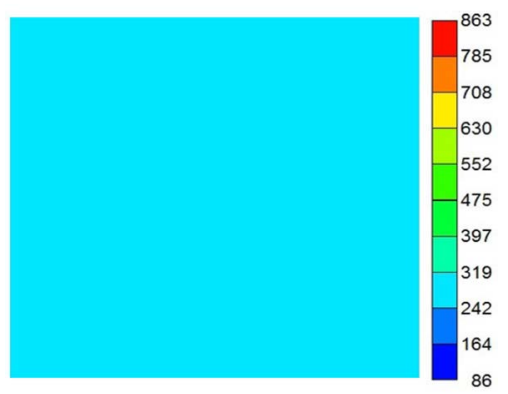

Figure 2. Initial temperature $\left({ }^{\circ} \mathrm{F}\right)$ of the reservoir.

Heater temperature was set to $800^{\circ} \mathrm{F}$ to heat-up the oil shale formation. The heat was slowly transferred to oil shale formation. At this stage, the conduction and convection were the main heat dissipation processes. Figure 3 shows the temperature distribution in the studied reservoir at the 200th day.

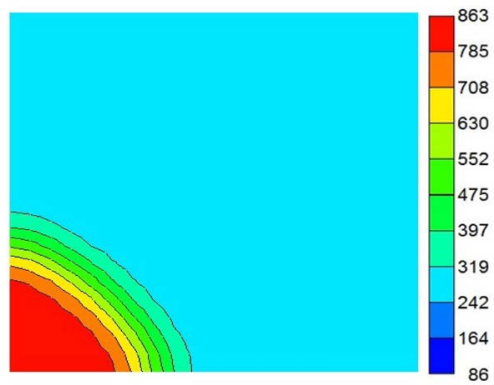

Figure 3. Temperature distribution in the reservoir on the 200th day in ${ }^{\circ} \mathrm{F}$.

Figure 4 shows the temperature distribution into the reservoir at the 500th day. It can be seen that the temperature of the hottest parts of the reservoir is around $800^{\circ} \mathrm{F}$. Since kerogen has already started to convert to fluid at this stage heat transfer is also accelerated.

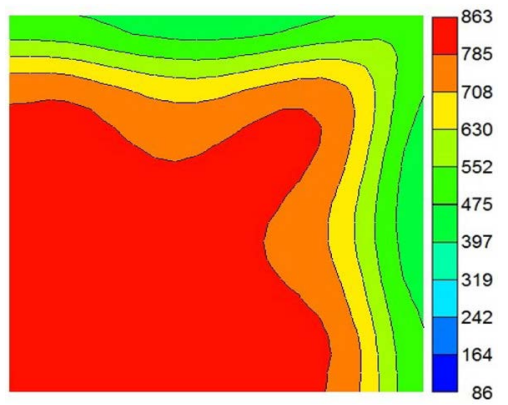

Figure 4. Temperature distribution in the reservoir on the 500 th day in ${ }^{\circ} \mathrm{F}$. 
The same mechanism can also be seen from Figure 5 which shows the oil and gas production from in-situ conversion of kerogen as a function of temperature. The peak production was observed at the 550th day.

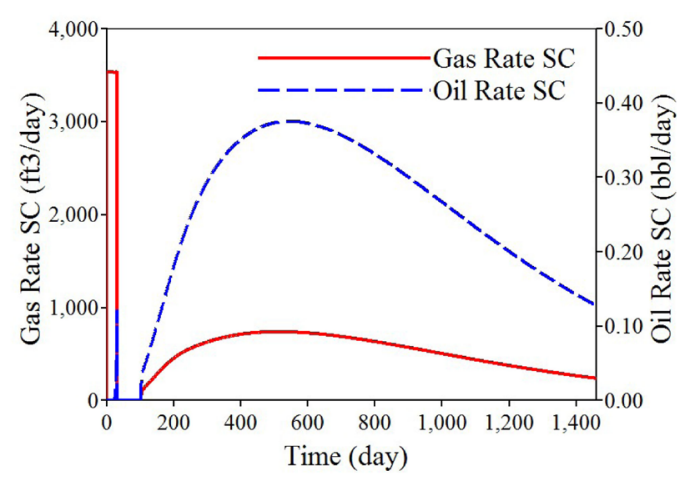

Figure 5. Oil and gas production by conversion of in-situ kerogen as a function of temperature.

\section{Conclusion}

A comprehensive mathematical and numerical simulation study regarding heat dissipation in an oil shale reservoir has been carried out carefully. It reveals that while modeling the heat dissipation and transportation in an oil shale reservoir; conduction, convection, dispersion, advection and diffusion processes are needed to be incorporated properly. Without fully acknowledged of these processes, accurate heat dissipation and transportation modeling of in-situ conversion process of oil shale cannot be achieved.

\section{Acknowledgements}

This study was supported by the National Science Foundation (51674279, 51804328), Major National Science and Technology Project (2017ZX05009-001, 2017ZX05069, 2017ZX05072) Shandong Province Key Research and Development Program (2018GSF116004), Shandong Province Natural Science Foundation (ZR2018BEE008, ZR2018BEE018), Fundamental Research Funds for the Central Universities (18CX02168A), China Postdoctoral Science Foundation (2018M630813), Postdoctoral Applied Research Project Foundation of Qingdao city (BY201802003).

\section{Conflicts of Interest}

The authors declare no conflicts of interest regarding the publication of this paper.

\section{References}

[1] Brandt, A.R. (2008) Converting Oil Shale to Liquid Fuels: Energy Inputs and Greenhouse Gas Emissions of the Shell in Situ Conversion Process. Environmental Science \& Technology, 42, 7489-7495. https://doi.org/10.1021/es800531f

[2] Demirbas, A. (2016) Conversion of Oil Shale to Liquid Hydrocarbons. Energy 
Sources, Part A: Recovery, Utilization, and Environmental Effects, 38, 2698-2703. https://doi.org/10.1080/15567036.2015.1115925

[3] Bai, F., Sun, Y., Liu, Y. and Guo, M. (2017) Evaluation of the Porous Structure of Huadian Oil Shale during Pyrolysis Using Multiple Approaches. Fuel, 187, 1-8. https://doi.org/10.1016/j.fuel.2016.09.012

[4] El-Mofty, S.E., Khairy, N., El-Kammar, A.M. and El-Midany, A.A. (2018) Effect of Mineralogical Composition and Kerogen Content on Oil Shale Natural Floatability. Energy Sources, Part A: Recovery, Utilization, and Environmental Effects, 40, 1144-1152. https://doi.org/10.1080/15567036.2018.1474298

[5] Haijun, F., Zafar, A., Alam, S.G., Kashif, M. and Mehmood, A. (2017) Analyses of Nature of Fault through Production Data. Open Journal of Yangtze Gas and Oil, 2, 176-190. https://doi.org/10.4236/ojogas.2017.23014

[6] Mehmood, A., Yao, J., Fan, D., Bongole, K., Liu, J. and Zhang, X. (2019) Potential for Heat Production by Retrofitting Abandoned Gas Wells into Geothermal Wells. PLoS ONE, 14, e0220128. https://doi.org/10.1371/journal.pone.0220128

[7] Taylor, O.J. (1987) Benefits, Requirements and Effects of Different Levels of Oil-Shale Development. Oil Shale, Water Resources, and Valuable Minerals of the Piceance Basin, Colorado, the Challenges and Choices of Development, USGS. https://doi.org/10.3133/pp1310

[8] Wu, Y.-S. and Pruess, K. (2000) Numerical Simulation of Non-Isothermal Multiphase Tracer Transport in Heterogeneous Fractured Porous Media. Advances in Water Resources, 23, 699-723. https://doi.org/10.1016/S0309-1708(00)00008-7

[9] Zafar, A. and Fan, H.J. (2017) Combination of Geological, Geophysical and Reservoir Engineering Analyses in Field Development: A Case Study. International Journal of Environmental, Chemical, Ecological, Geological and Geophysical Engineering, 11, 36-43.

[10] Zafar, A., et al. (2019) The Numerical Simulation and Well Bore Modeling of Steam Injection and Stored Heat Recovery from Light Oil Reservoir. Energy Sources, Part A: Recovery, Utilization, and Environmental Effects. https://doi.org/10.1080/15567036.2019.1676331

[11] Zafar, A., et al. (2019) The Numerical Simulation of Effects of Porosity, Permeability and Fluid Saturation on Heat Dissipation in an Oil Reservoir. 2nd International Conference of Arabian Journal of Geosciences, Tunisia, 25-28 November 2019.

[12] Zafar, A., et al. (2020) Tight Gas Production Model Considering TPG as a Function of Pore Pressure, Permeability and Water Saturation. Petroleum Science. https://doi.org/10.1007/s12182-020-00430-4

[13] Han, J., Sun, Y., Guo, W., Li, Q. and Deng, S. (2019) Characterization of Pyrolysis of Nong'an Oil Shale at Different Temperatures and Analysis of Pyrolysate. Oil Shale, 36, 151-170. https://doi.org/10.3176/oil.2019.2S.06

[14] Jia, J., Qian, R. and He, J. (2019) Achieving Resilience and Sustainability through Innovative Design for Oil Shale Pyrolysis Process Model. Oil Shale, 36, 142-150. https://doi.org/10.3176/oil.2019.2S.05

[15] Kashif, M., Cao, Y., Yuan, G., et al. (2019) Sedimentological Impact on Reservoir Quality of Es1 Sandstone of Shahejie Formation, Nanpu Sag, East China. Arabian Journal of Geosciences, 12, 545. https://doi.org/10.1007/s12517-019-4671-y

[16] Liu, D.X., Wang, H.Y., Zheng, D.W., Fang, C.H. and Ge, Z.X. (2009) World Progress of Oil Shale In-Situ Exploitation Methods. Natural Gas Industry, 29, 128-132.

[17] Mehmood, A., Yao, J., Fun, D.Y. and Zafar, A. (2017) Geothermal Energy Potential 
A. Zafar et al.

of Pakistan on the Basis of Abandoned Oil and Gas Wells. Journal of Petroleum \& Environmental Biotechnology, 7, 332. https://doi.org/10.4172/2157-7463.1000332

[18] Mehmood, A., Yao, J. and Fun, D.Y. (2017) Future Electricity Production from Geothermal Resources Using Oil and Gas Wells. Open Journal of Yangtze Gas and Oil, 2, 191-200. https://doi.org/10.4236/ojogas.2017.24015 